\title{
Stoma Creation After Surgery for Rectal Cancer: Temporary or Permanent?
}

\author{
Jung Wook Huh \\ Department of Surgery, Samsung Medical Center, Sungkyunkwan University School of Medicine, Seoul, Korea
}

\section{See Article on Page 98-102}

In rectal cancer surgery, creation of diverting stomas can potentially minimize the fatal outcomes of anastomotic leakage, although it may not substantially decrease its incidence $[1,2]$. Several studies showing that a defunctioning stoma seems to be useful in preventing clinical anastomotic leakage and urgent reoperations in patients receiving a low anterior resection have been reported [1,3]; however, whether a diverting stoma itself can prevent anastomotic leakage independently is still a controversial issue. Rather, stoma creation in patients undergoing a low anterior resection after neoadjuvant chemoradiotherapy may be helpful for a patient's well-being because the predictable poor bowel function in the immediate postoperative period may be avoided.

Up to a quarter of patients who undergo sphincter-saving surgery with a temporary stoma may consequently remain in the permanent stoma status, including nonreversal conditions or re-creation of another stoma after stoma-closure surgery [4-7]. A review of the factors associated with a permanent stoma after a low anterior resection showed old age, anastomotic complications including leakage, radiation therapy, incurable local pelvic recurrence, systemic disease, and irreversible poor anal sphincter function after surgery to be significant [4-7].

The benefits of a stoma in mitigating the potential complications due to anastomotic problems/pelvic sepsis in low rectal cancer must be balanced against the potential disadvantages of ostomy-related complications and of its subsequent closure procedure. Although making a decision on whether or not to

Correspondence to: Jung Wook Huh, M.D.

Department of Surgery, Samsung Medical Center, Sungkyunkwan University School of Medicine, 81 Irwon-ro, Gangnam-gu, Seoul 135-710, Korea

Tel: +82-2-3410-1826, Fax: +82-2-3410-6980

E-mail: jungwook.huh@gmail.com

(C) 2015 The Korean Society of Coloproctology

This is an open-access article distributed under the terms of the Creative Commons Attribution NonCommercial License (http://creativecommons.org/licenses/by-nc/3.0) which permits unrestricted noncommercial use, distribution, and reproduction in any medium, provided the original work is properly cited. create a stoma based on these factors only is hardly possible, this issue should be discussed preoperatively so that permanent-stoma-creating surgery may be selected according to patient's condition, especially in more elderly patients who are receiving radiotherapy and who have a poor anal sphincter function preoperatively.

\section{CONFLICT OF INTEREST}

No potential conflict of interest relevant to this article was reported.

\section{REFERENCES}

1. Tan WS, Tang CL, Shi L, Eu KW. Meta-analysis of defunctioning stomas in low anterior resection for rectal cancer. Br J Surg 2009; 96:462-72.

2. Matthiessen P, Hallbook O, Rutegard J, Simert G, Sjodahl R. Defunctioning stoma reduces symptomatic anastomotic leakage after low anterior resection of the rectum for cancer: a randomized multicenter trial. Ann Surg 2007;246:207-14.

3. Montedori A, Cirocchi R, Farinella E, Sciannameo F, Abraha I. Covering ileo- or colostomy in anterior resection for rectal carcinoma. Cochrane Database Syst Rev 2010;(5):CD006878.

4. Kim YA, Lee GJ, Park SW, Lee WS, Baek JH. Multivariate analysis of risk factors associated with the nonreversal ileostomy following sphincter-preserving surgery for rectal cancer. Ann Coloproctol 2015;31:98-102.

5. Lim SW, Kim HJ, Kim CH, Huh JW, Kim YJ, Kim HR. Risk factors for permanent stoma after low anterior resection for rectal cancer. Langenbecks Arch Surg 2013;398:259-64.

6. Lee CM, Huh JW, Park YA, Cho YB, Kim HC, Yun SH, et al. Risk factors of permanent stomas in patients with rectal cancer after low anterior resection with temporary stomas. Yonsei Med J 2015; 56:447-53.

7. Seo SI, Yu CS, Kim GS, Lee JL, Yoon YS, Kim CW, et al. Characteristics and risk factors associated with permanent stomas after sphincter-saving resection for rectal cancer. World J Surg 2013; 37:2490-6. 